\title{
Historical Changes of Traditional Funeral Rites of the Yi Nationality
}

\author{
Kaihui Lu \\ Southwest Minzu Research Institute \\ Southwest Minzu University \\ Chengdu, China
}

\begin{abstract}
In the history of the Yi nationality, there were many kinds of burials, and cremation was the most important traditional one. Since the Han dynasty and throughout the dynasties, it has been recorded in Chinese literature that the $\mathbf{Y i}$ people were mainly cremated. After Ming and Qing dynasties, the central dynasty banned cremation and most of the Yi areas except Liangshan Yi district were forced to carry out land burial. At present, with the change of public policies, in order to save land resources, the $\mathrm{Yi}$ area, that was originally forced to be land burial, will gradually cremated, but its form is now different from the traditional Yi people's cremation. Liangshan Yi area, which has always kept traditional cremation, is also faced "changing customs" of the government due to its prominent economic consumption. Therefore, although the funeral ceremony is stable, it is bound to undergo drastic changes when confronted with public policies.
\end{abstract}

\section{Keywords - the Yi nationality; funeral rites; changes}

\section{INTRODUCTION}

Funeral rites are the special forms and customs dealing with the body and soul of the dead, formed by a nation in the long history development. It is the worship of the ancestral spirit, the concrete embodiment of ancestor worship that arises from the kinship consciousness, the external manifestation of ancestral belief and soul concept. The characteristic of its worship behavior is to deify and worship ancestors; it has the identity of their own ethnic group and exclusiveness of other ethnic group. ${ }^{1}$ At the same time, as professor Zhao said, it has the characteristics of relative stability, wide popularity and strong inheritance. The funeral custom is passed down from generation to generation, and will gradually evolve into a symbol that different from other ethnic groups. Although the environment in which the funeral custom was later generated changed, the change in the funeral custom is still not obvious. ${ }^{2}$

About the study on the funeral rites of the Yi nationality, in Ma Xueliang and Yu Jinxiu's Investigation report on the primitive religion of the Yi nationality, a large number of the complete funeral rites process of Sichuan, Yunnan and

Jiang Lisong, " Introduction of cultural anthropology ", Southwest China Normal University Press, 2010.

Zhao Zehong, "Returning to the world -- a study on the funeral culture of ethnic minorities in pu 'er region", Yunnan University Press, 2008
Guizhou were recorded, and there were many discussions and detailed descriptions of the ceremony, which are very precious. In the Integration of the original religious materials of various ethnic groups in China (Yi nationality volume) edited by $\mathrm{He}$ Yaohua, the funeral rites of various $\mathrm{Yi}$ nationality regions are discussed in detail. It covers the funeral situations of $\mathrm{Yi}$ nationality in various regions in the broadest range, and also collected many research results, providing rich materials for people to study the traditional funeral of Yi nationality. Huang Chengzong sorted out the Yi burial customs in the pre-liberation, Tang, Yuan, Ming, and Qing dynasties, and pointed out that the ancient Yi burial customs of Yunnan, Guizhou and Sichuan were mainly cremation. ${ }^{3}$ Deng Limu made an investigation on the funeral culture of Yi nationality from northwest Yunnan to central Yunnan to Kunming, and made a summary of its changes, he thought the funeral of the $\mathrm{Yi}$ nationality should not be separated simply by "tradition" and "modernity", but should be considered from the diversity of culture. ${ }^{4}$ According to the soul view of the Yi people, Ma Shihuo explained the origin of the worship and burial customs of the Yi people's ancestors, analyzed the negative impact of luxurious burial on the economy of the $\mathrm{Yi}$ people, and put forward suggestions on reforming the burial customs. Other relevant studies, mostly taking a place or village as an example, discuss the change, function, and view of life, death and other aspects of the funeral; or independently study the mantra, dance, music, sorcery, and human relations, etc. of the funeral rites. There is little people tease out the overall changes of the funeral rites of the Yi nationality, which will be the intention of this paper.

\section{OVERVIEW OF THE YI NATIONALITY AND ITS FUNERAL RITES}

The Yi nationality is an ancient nationality with a long history and splendid civilization in southwest China. According to the 2010 census, the population of the $\mathrm{Yi}$ nationality is over 8.71 million. It is mainly distributed in the north and south of Jinsha River; from Dadu River in the

\footnotetext{
Huang Zongze, “A preliminary study on Yi people's ancient burial customs”, Guizhou Minzu Yanjiu, 1982.

Deng Limu, "A brief analysis on funeral culture changes of the Yi nationality", Journal of Yunnan University(Social Sciences Edition), No.4, 2000.
} 
north and Honghe River in the south are the main areas where the Yi people live. In terms of administrative division, the Yi nationality is mainly distributed in Yunnan, Sichuan, Guizhou and Guangxi provinces. Among them, Yunnan is the most distributed province, the Yi people centralized in Chuxiong, Honghe, Zhaotong, Lijiang, Yuxi, Dali and Qujing; second largest is Sichuan, it has Liangshan Yi autonomous prefecture, which is the largest Yi community in China; Guizhou Yi people mainly live in Bijie area, Liupanshui city and Anshun area; Guangxi Yi people mainly live in Longlin and Napo counties. The rest are widely scattered and small settled throughout the country, living with other ethnic groups. ${ }^{5}$

The funeral ceremony of the Yi people is regarded as the most important thing in their life. The Yi people believe that people should return to their ancestral home to reunite with their ancestors after their death, which is the most beautiful world in the universe. After the death of the ancestors, they become the protectors of the later generations, which is the main reason for the blessing of the living. Therefore, funeral rites are very important for the deceased to reach the ancestral world, so it is not hard to understand why the scale of traditional funeral rites of Yi nationality is so grand.

Historically, the funeral methods of the Yi nationality include cremation, rock burial, water burial, coffin burial, etc., cremation is the main way for normal death. There are three kinds of rock burials: one is to bury the coffin in the cave and seal the entrance of the cave with stone, and there are epitaphs in it; the other is to put the ashes in pottery jar and put it in caves; third, place the coffin in the cave. According to Bai Xingfa's investigation, the Yi people in Fumin County used to put ashes of the dead into pottery jar and then put it into cave, sprite tablet is also placed in the cave. ${ }^{6}$ Water burials are only used for unnatural deaths, such as aborted babies or people who die in infancy, by wrapping their bodies in cloth and putting them in water, this is the way to avoid the recurrence of miscarriage and people who die young. Pottery burial, also known as "stand burial" and "heavenward burial", refers to the use of a 6-foot-high altar jar to put the deceased into a upright position, buried in the soil, and built into a tomb mound, this kind of burial method has been used in the history of the Sani branch of Kunming Stone Forest Yi nationality.

However, cremation is still the most representative traditional form of the $\mathrm{Yi}$ nationality burial, because it originated from the Yi nationality, and is the most common and extensive in the Yi nationality society, it also has the most lasting history, the relevant literature records are very rich. Due to the wide population distribution, diverse branches and different living environments of the Yi nationality, the burial customs of the Yi nationality vary from place to place, but generally they are the same. After the Ming and Qing dynasties, the traditional funeral rites of

State Ethnic Affairs Commission of the PRC, "Overview of the Yi Nationality", http://www.seac.gov.cn/col/col571/index.html.

6 Bai Xingfa, "Culture History of the Yi Nationality", The Ethnic Publishing House of Yunnan, 2002. the Yi nationality underwent drastic changes; land burial and cremation have become two main forms of burial.

\section{THE CREMATION HiSTORY OF THE Yi NATIONALITY}

According to archaeological data, the custom of cremation dates back to the Neolithic age, as for the funeral customs in the history of the Yi nationality, there are many records in the Chinese history books, the earlier book is The History of Yunnan written by Fan Zhuo in Tang dynasty: "Wu and other minorities are not buried in the grave, all the dead were burned three days after their deaths, the ashes covered by the soil, or kept in pottery jar". ${ }^{7}$ It is said that during the Nanzhao period of the Tang dynasty, the Yi people did not have to be buried in a tomb, all the dead were burned three days after their deaths and the ashes put into pottery jar. Another book Youyang Miscellany, chapter Jingyi written by Duan Chengshi in Tang dynasty recorded the burial rites of Jiulao, described it this way: "black fungus $\mathrm{Yi}$, the dead was bent and burnd, the ashes buried". Jiulao is today's Shiqian County in Guizhou, this indicating that the $\mathrm{Yi}$ people were also cremated at that time. Here also mentioned the details of burial "bend and burn," means bent the body. At present, in Daliang Mountain and Xiaoliang Mountain Yi district, this detail has not changed, before the deceased buried, the deceased should be bent. It can be seen from the above historical materials that the funeral custom of the Yi nationality in the Tang dynasty was to burn the body three days after death, and the ashes were buried directly, or put into a pottery jar and then to bury.

The funeral custom of Yi nationality in Song dynasty, recorded in the book of Taiping Imperial Encyclopedia volume 556 by Li Fang of the Northern Song dynasty "Yi people in Jianning County (today's Qujing area of Yunnan province), when they bury the deceased, they put the deceased on piles of firewood and then burn him or her. If the smoke goes straight into sky, cattle and sheep were killed, and people happily congratulated each other; if there is wind and the smoke goes around, people will be sad and cry." It also recorded in the book of Taiping Huan Yu Ji, Xizhou volume 80 written by Yue Shi in Song dynasty, black fungus Yi also have this kind of burial custom. The above two historical materials are similar in content. These all improved that after the Yi people died, the deceased was put on a pile of firewood and burned. If the smoke goes up straight, it is regarded as good luck, and people sacrificed oxen and sheep and drank together; if the fire smoke goes around, it is regarded as bad luck, relatives will be sad and cry. The Yi people, who are still cremated today, share the same view.

In early Yuan dynasty, History of Yunnan, customs of minorities written by Li Jing recorded that when the chief of Yi people dead, his body will be wrapped in leopard skin and then cremated, the ashes will be buried in the mountain, only his descendants would know where he was buried. During the funeral rites, "all relatives would join together, thousands of cattle and sheep were sacrificed, or at least over hundreds,

\footnotetext{
Zhu Wenxu, "Primitive religion and culture of the Yi nationality", Minzu University of China Press, 2002.
} 
and was very lively. ${ }^{8}$ Thus it can be seen that after the death of $\mathrm{Yi}$ people in Yuan dynasty, they were also burned by wrapping the bodies and then hidden the ashes in the mountains, only relatives knew where they were buried. Also thousands of cattle and sheep were sacrificed, or at least hundreds, we could know how grand the rite was, and the burial custom is the same as the Daliang Mountain and Xiaoliang Mountain today.

Tian Qi in Ming dynasty wrote the book History of Yunnan and recorded Luo wu is cremated, "Luo wu" refers to the Yi nationality in history. Investigation of Minorities written by Fan Shouji in Ming dynasty recorded the deceased was not buried in coffin, but wrapped in silk and then burned, ashes covered with soil, the carved wood wrapped with wool entwined represented ancestors. On June $24^{\text {th }}$ every year, sacrificed oxen and sheep, and people lit torch and drank together in the night. ${ }^{9}$ Also like the Ming dynasty Luoxiong State, Yi people not buried in coffin but carried to the wild and burned, relatives gathered together and sacrificed animals, only the bones will be collected and only the descendants would know where he or she was buried. Although the Yi people live in different places, the customs were the same, not only in Luoxiong State. ${ }^{10}$ Here, it is also mentioned that after the funeral ceremony in the Ming dynasty, oxen and sheep were killed to sacrifice the ancestors at the torch festival every year, this is consistent with today's situation. In fact, the Yi people pay tribute to their ancestors before most of the important festivals and activities, for example, the torch festival, the Yi New Year, special days or when there is important occasion in the family, people must first pay tribute to the ancestors. In author's hometown Zhaotong, when people return home after serious sickness, in order to thank the relatives and neighbors, before the banquet, food should be first served to respect ancestors.

In addition to cremation, the records of the funeral of the Yi nationality in the Qing dynasty also recorded that the large-scale ancestor worship ceremony held within a few years after the cremation. During this period, people dressed up to attend the rite, offered killed animals and wine to the dead, and held horse racing and other activities. History of Yuexi State, the culture of minorities written in year of Guangxu recorded that the Yi deceased not buried in coffin but was burned, three years later, they asked the Yi monk to recite sutras to release the soul of ancestor from purgatory, this called Zuo Bai. People first to cut wood pieces to notify close and distant relatives, all of them would come with animals, wear shining clothes, black and white wool felt, male with gold and silver decoration, women wearing gold and silver cape and colorful dress, came by riding horses. After eating and drinking, a horse-riding race in circle was held. The "Zuo Bai" here is actually today's "ni mu cuo bi"

\footnotetext{
8 Zhang Bangwei, "Funeral customs of ethnic minorities in the
} Liao, Song, Xixia and Jin dynasties", Journal of Sichuan University (social and science), No. 4, 1997

$9 \quad$ Huang Zongze, “A preliminary study on Yi people's ancient burial customs”, Guizhou Minzu Yanjiu, 1982.

10 Cai Hua, "Daoism and traditional Yi culture", The Ethnic Publishing House, 1st edition, 2005, P.10. in Liangshan $\mathrm{Yi}$ district, the large-scale ancestor worship ceremony.

To sum up, cremation has been widely practiced in the history of the Yi nationality in the Tang, Song, Yuan, Ming, Qing dynasties, and in Yunnan, Guizhou, Sichuan and some other places recorded in the literature, the deceased burned in the wild, the ashes buried in the ground or hidden in deep mountain caves. Sheep and oxen were sacrificed in the funeral; its basic features have hardly changed much. And so far, the Yi people who live in Liangshan and along the Jinsha River in Yunnan still practice this custom.

\section{CONCLUSION}

The great changes in the traditional funeral rites of the $\mathrm{Yi}$ nationality took place in the late Ming dynasty and the early Qing dynasty, the central dynasty banned cremation. For example, in the reign of emperor Daoguang in the Qing dynasty, "20 bans to the people" stipulated that: "people who burned the deceased are often forbidden by the local government, if people dare to commit crimes again, they shall be given heavier punishment. ${ }^{11}$ After Yi clan came under the ruling of central government officials in Qing dynasty, the power of the Yi hereditary headmen lost their power, and the ruler stipulated strict prohibition, the Yi people in Yunnan and Guizhou were forced to gradually change cremation to coffins burial. ${ }^{12}$

From the late Qing dynasty to the Republic of China, the Yi people in Zhaotong, Yunnan, had been buried in coffins and built a tomb with earth and stone, a few powerful heanmen and rich black Yi people paid great attention to the repair of the tomb. Before burial, monks and Taoist priests are invited to make a seven-day or nine-day religion activity to pay tribute to the dead, all descendans worn traditional clothes and go to the burial site. Except religion activity, the ceremony is mostly influenced by the customs of the Han nationality.

Up to now, most of the Yi people in Yunnan, Guizhou and Guangxi chose land burial, which has been passed down from generation to generation and has become another traditional burial style. But this new tradition will be reformed as the government believes that land burial is a waste of land resources, cremation is advocated and now is being carried out. However, due to historical and geographical reasons, the complete traditional cremation customs were still intacted in Liangshan, Sichuan province and Ninglang, Yunnan province, and the procedures are basically the same as those recorded in the literature.

At present, the Yi people in Daliang Mountain and Xiaoliang Mountain still attach great importance to the funeral of their relatives, and still the descendans do their best to make it ceremonious, the lowest cost is tens of thousands of RMB. With modernization accelerating and government intervention, this traditional funeral is changing, because Liangshan $\mathrm{Yi}$ district is still in the position of the

\footnotetext{
11 History of Dading County, art and culture history.

12 Zhu Wenxu, "Primitive religion and culture of the Yi nationality",
} Minzu University of China Press, 2002. 
poorest margin in China, it is the focus of the national poverty alleviation work. The government believes that costly funerals are also the cause of poverty. Therefore, the government promotes the transformation of customs, and the traditional funeral rites of the $\mathrm{Yi}$ nationality face new changes.

\section{REFERENCES}

[1] Bai Xingfa, "Culture History of the Yi Nationality", The Ethnic Publishing House of Yunnan, 2002.

[2] Zhu Wenxu, "Primitive religion and culture of the Yi nationality", Minzu University of China Press, 2002.

[3] Huang Zongze, "A preliminary study on Yi people's ancient burial customs”, Guizhou Minzu Yanjiu, 1982.

[4] Zhang Bangwei, "Funeral customs of ethnic minorities in the Liao, Song, Xixia and Jin dynasties", Journal of Sichuan University (social and science), No. 4, 1997.

[5] Cai Hua, "Daoism and traditional Yi culture", The Ethnic Publishing House, 2005.

[6] Deng Limu, "A brief analysis on funeral culture changes of the Yi nationality", Journal of Yunnan University(Social Sciences Edition), No.4, 2000. 